\title{
Adubação nitrogenada para o milho cultivado em sistema plantio direto, no Estado de Alagoas
}

\author{
Simério C. S. Cruz ${ }^{1}$, Francisco R. da S. Pereira ${ }^{1}$, José R. Santos ${ }^{2}$, Abel. W. de Albuquerque ${ }^{2}$ \& Rodrigo G. Pereira ${ }^{3}$
}

\begin{abstract}
RESUMO
Objetivou-se, neste trabalho, avaliar os efeitos de doses de $\mathrm{N}$ sobre os componentes de produção da cultura do milho cultivado em Sistema Plantio Direto. Utilizaram-se quatro doses de nitrogênio $\left(0,40,80\right.$ e $\left.120 \mathrm{~kg} \mathrm{ha}^{-1}\right)$ e cinco cultivares (AG-9010, TRACTOR, DOW-8550, DKB-395 e AL-34). Todos os tratamentos, exceto a testemunha, receberam 20, 115,60 e $4 \mathrm{~kg} \mathrm{ha}^{-1}$ de N, $\mathrm{P}_{2} 0_{5}$ e $\mathrm{K}_{2} \mathrm{O}$ e $\mathrm{Zn}$, respectivamente. O delineamento estatístico foi em blocos casualisados com quatro repetições em esquema de parcelas subdivididas. Os componentes da produção estudados, foram: população final de plantas por hectare, comprimento de espigas, número de fileira de grãos por espigas, número de espigas e massa de 100 grãos. As produtividades dos materiais utilizados no experimento variaram de $1.900 \mathrm{~kg} \mathrm{ha}^{-1}$ na testemunha a $5.662 \mathrm{~kg} \mathrm{ha}^{-1}$ para a maior dose de N (120 kg ha-1). Observou-se que, do ponto de vista de rentabilidade, as cultivares DOW-8550 e AG-9010 foram as mais promissoras; contudo, conclui-se que a utilização de $120 \mathrm{~kg} \mathrm{ha}^{-1}$ de N permitirá ao agricultor retorno econômico da adubação nitrogenada. Os híbridos e a variedade utilizados mostraram alta eficiência na utilização do $\mathrm{N}$ aplicado, sendo os híbridos mais responsivos que a variedade.
\end{abstract}

Palavras-chave: cultivares, níveis de adubação, manejo do solo

\section{Nitrogen fertilization for corn cultivated under a no-tillage system in the State of Alagoas, Brazil}

\begin{abstract}
The objective of this work was to evaluate the effects of nitrogen doses upon production components of corn cultivated under a no-tillage system. Four nitrogen rates $\left(0,40,80\right.$ and $\left.120 \mathrm{~kg} \mathrm{ha}^{-1}\right)$ and five cultivars (AG-9010, TRACTOR, DOW-8550, DKB-395 and AL-34) were used. For all treatments, except for the control 20, 115, 60 and $4 \mathrm{~kg} \mathrm{ha}^{-1}$ of N, $\mathrm{P}_{2} \mathrm{O}_{5}, \mathrm{~K}_{2} \mathrm{O}$ and $\mathrm{Zn}$ were applied, respectively. The statistical design was the completely randomized block with four replications in a split plot scheme. The yield components studied were: plant population at harvest, ear length, number of grain rows per ear, ear number, and mass of 100 grains. The yield of the germoplasm varied from 1,900 kg ha-1 for the control to $5,662 \mathrm{~kg} \mathrm{ha}^{-1}$ for the highest $\mathrm{N}$ dose $\left(120 \mathrm{~kg} \mathrm{ha}^{-1}\right)$. For yield, it was observed that the hybrids DOW-8550 and AG-9010 were the most promising. It may be concluded that the economic return of the $\mathrm{N}$ fertilization can be reached with a $120 \mathrm{~kg} \mathrm{ha}^{-1}$ dose. Both hybrids and cultivars used showed high efficiency in the use of the applied N, the hybrids being more responsive than the varieties.
\end{abstract}

Key words: cultivar, levels of fertilization, soil management

1 Doutorando FCA/UNSP, Fazenda Experimental Lageado, Bairro Jardim Paraíso, CP 237, CEP 18603-970, Botucatu, SP. Fone: (14) $3811-7132$. E-mail: simerio_cruz@yahoo.com.br

2 UFAL. Fone: (82) 3261-1776. E-mail: santosjr2002@yahoo.com.br, awa@fapeal.br

${ }_{3}^{3}$ Mestrando do CECA/UFAL, Campos Delza Gitai, km 85, CEP 57100-000, Rio Largo, AL. Fone: (82) 3261-1776. E-mail: rgperira@ yahoo.com.br 


\section{INTRODUÇÃO}

Por desempenhar papel significativo na produção nacional de grãos, o milho se destaca como influenciador direto na economia de qualquer Estado importador deste cereal. No Brasil, a cultura se sobressai em virtude de apresentar a maior área cultivada entre os principais produtos agrícolas $(12,4$ milhões de hectares) e a maior produção de grãos (42,16 milhões de toneladas). O Estado de Alagoas vem apresentando grandes perdas de divisas em razão de não ser, ainda, auto-suficiente na produção deste cereal, ficando sua produtividade média em torno de $344 \mathrm{~kg} \mathrm{ha}^{-1}$, enquanto nos Estados do Sul, Sudeste e Centro Oeste do Brasil, as produtividades médias atingem valores acima de $4000 \mathrm{~kg} \mathrm{ha}^{-1}$ (Agrianual, 2005).

A baixa produtividade do milho no Estado de Alagoas se deve, entre outros aspectos, ao manejo inadequado do solo, que facilita a erosão e a adubação inadequada.

Quanto ao sistema de manejo do solo para cultivo do milho se dispõe, atualmente, do Sistema Plantio Direto (SPD) que se caracteriza pela semeadura em solo não revolvido e coberto pela palha da cultura anterior como alternativa econômica e ecologicamente viável para a produção de grãos em ambiente tropical (Bernardi et al., 2003).

O nitrogênio $(\mathrm{N})$ não é apenas o nutriente exigido em maior quantidade e o que mais influencia na produtividade do milho, mas, também, o que mais onera o custo de produção (Silva et al., 2005; Amado et al., 2002).

Fernandes et al. (1998) e Coelho et al. (1992) relatam que a produção de grãos de milho aumentou de forma quadrática com o aumento das doses de $\mathrm{N}$. A dose de $\mathrm{N}$ para máxima eficiência econômica ( $90 \%$ da máxima produção) foi de $80 \mathrm{~kg} \mathrm{ha}^{-1}$, bem inferior, portanto, às doses mais elevadas testadas.

Estudos realizados por Ferreira (1997), com relação ao efeito da adubação com quatro níveis de $\mathrm{N}$ (0, 70, 140 e $210 \mathrm{~kg} \mathrm{ha}^{-1}$ ) sobre a qualidade de grãos de milho híbrido, mostraram que a produção de grãos aumentou com incremento das doses de N, obtendo-se a máxima produção com a dose de $200 \mathrm{~kg} \mathrm{ha}^{-1}$; portanto, o manejo da adubação nitrogenada a fim de aumentar sua eficiência, é fator importante na busca de melhores produtividades; tal manejo tem sido a parte mais desafiante e limitante na produção de milho, principalmente nos solos das regiões que, em geral, apresentam baixa capacidade de suprimento de N (Silva et al., 2005).

Não se dispõe de dados para recomendação de adubação para a cultura do milho no Estado de Alagoas, em Sistema de Plantio Direto (SPD), que é um sistema pouco utilizado no Nordeste do Brasil; sabe-se, contudo, que a utilização de sistemas de manejo com menor revolvimento do solo promove maior atividade biológica, aumento nos teores de carbono orgânico, $\mathrm{N}$ total e outros nutrientes (Bayer et al., 1997); todavia, o não-revolvimento do solo promove modificações na ciclagem dos nutrientes, sendo o $\mathrm{N}$ o mais afetado uma vez que, com a decomposição mais lenta dos resíduos vegetais deixados na superfície do solo, processos de imobilização, mineralização, lixiviação, volatilização e desnitrificação, são alterados (Lara Cabezas et al., 2000), reco- mendando-se aplicações de doses de N 20 a 30\% maiores na semeadura no sistema plantio direto (Bayer, 1993 apud Müller Mai et al., 2003).

Conforme Sá (1993) a maior perda de N no SPD pode ser compensada pela liberação lenta e gradual do material orgânico. Uma alternativa para minimizar o problema, segundo Gonçalves et al. (2000), é manter sempre o solo com cobertura vegetal, com a função de reciclagem de nutrientes na sua biomassa e de cobertura do solo. Objetivou-se neste trabalho, avaliar doses de $\mathrm{N}$ e seus efeitos na produtividade de grãos de milho, cultivado em Sistema Plantio Direto.

\section{MATERIAL E MÉTODOS}

O experimento foi conduzido na área experimental do Campus Delza Gitaí, pertencente ao Centro de Ciências Agrárias - CECA, da Universidade Federal de Alagoas UFAL. As coordenadas geográficas de referência são: Latitude Sul 9०29' 45”' e Longitude Oeste 35 49' 54”. A altitude do local do experimento é de 165 m com 3\% de declividade; o clima, de acordo com a classificação de Koeppen, é do tipo As, tropical chuvoso, com verões secos.

O solo onde as parcelas experimentais foram instaladas foi classificado como Latossolo Amarelo coeso distrófico (EMBRAPA, 1999), cujas características químicas, determinadas analiticamente, se encontram na Tabela 1.

Tabela 1. Análise química do solo na profundidade 0-20 cm, amostrado antes da instalação do experimento

\begin{tabular}{|c|c|c|c|c|c|c|c|c|}
\hline pH & MO & ${ }^{*} P$ & $\mathrm{H}+\mathrm{Al}$ & K & $\mathrm{Ca}$ & $\mathrm{Mg}$ & $T$ & V \\
\hline $\mathrm{H}_{2} \mathrm{O}$ & $g \mathrm{dm}^{-3}$ & $\mathrm{mg} \mathrm{dm}^{-3}$ & \multicolumn{5}{|c|}{$\mathrm{cmol}_{\mathrm{c}} \mathrm{dm}^{-3}$} & $\%$ \\
\hline 4,8 & 16 & 22 & 3,7 & 0,19 & 0,9 & 0,6 & 5,4 & 31 \\
\hline
\end{tabular}

Os tratamentos consistiram da utilização de cinco cultivares de milho (AL-34, DKB-395, DOW-8550, TRACTOR e AG-9010) e quatro doses de nitrogênio (0, 40, 80, e $120 \mathrm{~kg} \mathrm{ha}^{-1}$ de $\mathrm{N})$. O delineamento estatístico foi em blocos casualisados com quatro repetições, cuja área de cada parcela era de $96 \mathrm{~m}^{2}$ (4,8 x 20 m). A cultivar AL-34 é uma variedade produzida pela CATI-SP; as demais são híbridos comerciais, considerados de alta produtividade. $\mathrm{O}$ experimento obedeceu ao esquema de parcelas subdivididas, ficando as cultivares nas parcelas e as doses de nitrogênio nas sub-parcelas.

Por ocasião da semeadura toda a área experimental recebeu 20, 115, 60 e $4 \mathrm{~kg} \mathrm{ha}^{-1}$ de $\mathrm{N}, \mathrm{P}_{2} \mathrm{O}_{5}, \mathrm{~K}_{2} \mathrm{O}$ e $\mathrm{Zn}$, respectivamente, na forma de sulfato de amônio, superfosfato triplo, cloreto de potássio e sulfato de zinco; no tratamento sem adubação nitrogenada foi suprimida a dose de N; esta adubação foi realizada no sulco de plantio, enquanto na adubação referente aos tratamentos se aplicaram 0, 20, 60 e $100 \mathrm{~kg} \mathrm{ha}^{-1}$ de $\mathrm{N}$ que, somados à dose de fundação, totalizaram as doses $0,40,80$, e $120 \mathrm{~kg} \mathrm{ha}^{-1}$; esta adubação foi realizada aos 29 dias após a semeadura, na forma de sulfato de amônio, sendo o adubo distribuído ao lado das plantas, ao longo da linha de semeadura. 
Antes da semeadura do milho o solo recebeu calagem, visando elevar a saturação por bases, para 70\% e se utilizaram 2,2 t ha-1 de calcário dolomítico. Três meses depois da calagem a área foi cultivada com crotalária (Crotalaria juncea), com o objetivo de produzir massa para cobertura vegetal, de forma a caracterizar o SPD. Quando a leguminosa se encontrava em pleno florescimento, foi triturada, utilizando-se roçadora com facas horizontais e deixada na superfície do solo.

A semeadura do milho foi realizada em junho, com semeadora a tração mecanizada com duas linhas individuais espaçadas 0,80 m pondo-se, por metro linear, 5 sementes; para o controle de plantas daninhas aplicou-se herbicidas de manejo na mistura Glyfosate de 2,5 $\mathrm{L} \mathrm{ha}^{-1}$ antes da semeadura do milho e $0,7 \mathrm{~L} \mathrm{ha}^{-1}$ do herbicida Triazina + Sulfoniluréia, em pós-emergência, 30 dias após a semeadura.

Utilizaram-se no controle de pragas, $75 \mathrm{~mL} \mathrm{ha}^{-1}$ do inseticida Deltamethrin, enquanto as formigas foram controladas, preventivamente, com formicidas granulados.

Para as medidas da altura de plantas e diâmetro do colmo, no estádio de florescimento, foram utilizadas 10 plantas por sub-parcela; já a colheita foi efetuada 117 dias após a semeadura, ocasião em que se avaliaram os componentes da produção e produtividade de grãos; os componentes da produção estudados, foram: população final de plantas por hectare, comprimento de espigas, número de fileira de grãos por espiga, número de espigas e massa de 100 grãos. A produtividade de grãos foi determinada colhendo-se as espigas da área útil da sub-parcela, perfazendo uma área de $16 \mathrm{~m}^{2}$ (3,2 $\times 5 \mathrm{~m})$.

Amostras de solo foram coletadas durante o estádio de florescimento do milho para determinação de $\mathrm{P}$ disponível, K, Ca, Mg, e Al trocáveis, $\mathrm{H}+\mathrm{Al}$, matéria orgânica e pH, coletadas na profundidade de $0-20 \mathrm{~cm}$, afastadas $20 \mathrm{~cm}$ da planta, na direção das entrelinhas; depois foram analisadas de acordo com a metodologia de análises descrita pela EMBRAPA (1997).

O rendimento máximo agronômico (RMA) da cultivar AL-34, com relação à produtividade, foi obtido com a derivada primeira da função $\mathrm{y}=-0,0002 \mathrm{x}^{2}+0,0466 \mathrm{x}+1,1472$, igualando-a a zero; para altura de planta e diâmetro do colmo os (MRA) das cultivares estudadas, foram obtidos através da derivada primeira das funções: $y=-0,00006 x^{2}+$ $0,0112 x+1,1643$ e $y=-0,0005 x^{2}+0,0849 x+16,066$ respectivamente; enfim, os dados originais foram submetidos a análise de variância a 5\% de probabilidade pelo teste $\mathrm{F}$, sendo as médias dos tratamentos comparadas pelo teste de Tukey; realizaram-se, também, análises de regressão para as doses de $\mathrm{N}$, cálculo para determinação da responsividade das cultivares e análise econômica.

\section{RESULTADOS E DISCUSSÃO}

Os resultados da análise química para a avaliação da fertilidade do solo no estádio de florescimento do milho estão na Tabela 2, na qual se verifica, de forma geral, melhoria no estado de fertilidade do solo quando comparados com os resultados da análise antes da instalação do experimento (Tabela 1). Melhorias em algumas característica químicas foram notadas, como: aumento do $\mathrm{pH}(4,8$ para 5,9), redução dos teores de $\mathrm{H}+\mathrm{Al}(3,7$ para 1,6$)$, elevação dos teores de potássio $(0,19$ para 0,28$)$, cálcio $(0,9$ para 2,3$)$ e magnésio $(0,6$ para 1,2$)$ e, conseqüentemente, aumento da saturação por base; essas modificações foram causadas pela calagem realizada para elevar a saturação por bases para 70\% e pela adubação realizada com base nas exigências nutricionais da cultura. Do ponto de vista de fertilidade, não se constatou nenhum elemento restritivo ao desenvolvimento da cultura do milho.

Tabela 2. Análise química do solo na profundidade $0-20 \mathrm{~cm}$

\begin{tabular}{|c|c|c|c|c|c|c|c|c|}
\hline \multirow{2}{*}{$\begin{array}{l}\mathrm{pH} \\
\mathrm{H}_{2} \mathrm{O}\end{array}$} & \multirow{2}{*}{$\underset{\mathrm{g} \mathrm{dm}}{\mathrm{MO}}$} & \multirow{2}{*}{ 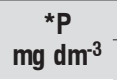 } & $\mathrm{H}+\mathrm{Al}$ & K & $\mathrm{Ca}$ & $\mathrm{Mg}$ & $T$ & V \\
\hline & & & \multicolumn{5}{|c|}{$\mathrm{cmol}_{\mathrm{c}} \mathrm{dm}^{-3}$} & $\%$ \\
\hline \multicolumn{9}{|c|}{ Antes do experimento } \\
\hline 4,8 & 16 & 22 & 3,7 & 0,19 & 0,9 & 0,6 & 5,4 & 31 \\
\hline \multicolumn{9}{|c|}{ No estádio de florescimento do milho } \\
\hline 5,9 & 16 & 22 & 1,6 & 0,28 & 2,3 & 1,2 & 5,4 & 70 \\
\hline
\end{tabular}

Os efeitos das doses de N sobre os componentes morfológicos se acham na Figura 1. As análises de regressão mostraram efeito quadrático para as doses utilizadas. Analisando-se as doses de $\mathrm{N}$ de máximo rendimento agronômico sobre os componentes morfológicos do milho, verificou-se que doses de $\mathrm{N}$ acima de 90 e $85 \mathrm{~kg} \mathrm{ha}^{-1}$ não contribuíram para o aumento da altura e diâmetro do colmo, respectivamente. O nitrogênio está associado, dentre outras funções na planta, ao crescimento vegetativo (Karlen et al., 1988).
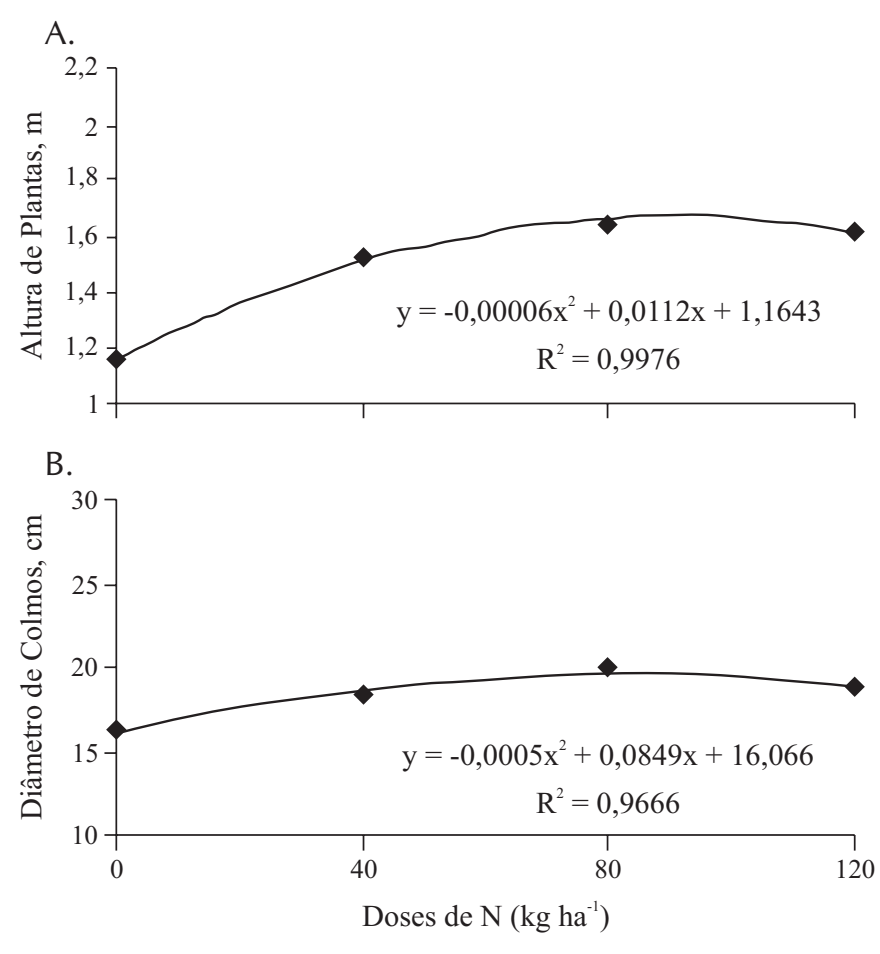

Figura 1. Altura de plantas (A) e diâmetro de colmos (B) em cultivares de milho, em função das doses de $\mathrm{N}$ 
Silva et al. (2003), estudando os efeitos da aplicação de doses de nitrogênio $\left(0 ; 40 ; 80\right.$ e $\left.120 \mathrm{~kg} \mathrm{~N} \mathrm{ha}^{-1}\right)$ na cultura do milho, constataram que a resposta da altura de plantas às doses de nitrogênio, foi positiva e descrita por equações do tipo $\mathrm{y}=\mathrm{a}+\mathrm{bx}-\mathrm{cx}^{2}$. Neste trabalho, o valor máximo para altura de plantas seria obtido fora do intervalo das doses de nitrogênio avaliadas (em torno de $130 \mathrm{~kg}$ de $\mathrm{N} \mathrm{ha}^{-1}$ ). O autor explica que, até determinadas doses de nitrogênio, a planta continua a crescer; depois que tais doses são atingidas, o auto-sombreamento das plantas, assim como o sombreamento mútuo entre plantas, deve contribuir para a redução do crescimento; entretanto, Tomazela (2005) evidenciou a ausência de resposta da cultura do milho à aplicação de doses elevadas de $\mathrm{N}$ em relação à altura de planta e diâmetro do colmo.

Os coeficientes de correlação entre os componentes morfológicos da planta e a produtividade de grãos, se encontram na Tabela 3; esses componentes estiveram correlacionados com a produtividade.

Tabela 3. Coeficientes de correlação entre os componentes morfológicos da planta e a produtividade de grãos de milho

\begin{tabular}{lcc}
\hline Cultivares & Altura da Planta & Diâmetro do Colmo \\
AL-34 & $0,94^{*}$ & $0,89^{*}$ \\
DKB-395 & $0,82^{*}$ & $0,61^{*}$ \\
DOW-8550 & $0,92^{*}$ & $0,68^{*}$ \\
TRACTOR & $0,84^{*}$ & $0,70^{*}$ \\
AG-9010 & $0,84^{*}$ & $0,42^{\text {ns }}$ \\
\hline
\end{tabular}

* Significativo $(p<0,05 ; N=16)$

Dentre os componentes morfológicos a altura de plantas não tem, geralmente, correlação com a produtividade. Cultivares modernas, com alto potencial produtivo são, em sua maioria, de porte baixo; também se pode encontrar materiais de porte alto com performances semelhantes aos baixos; neste trabalho, tal correlação foi possível pelo fato da produtividade estar diretamente relacionada com as doses de $\mathrm{N}$ aplicadas, ou seja, houve uma resposta positiva na altura com o aumento nas doses de $\mathrm{N}$ até o ponto de inflexão. A adição de $\mathrm{N}$ em plantas de milho estimula a proliferação do sistema radicular, com conseqüente desenvolvimento da parte aérea (Fancelli, 1997). Silva et al. (2005), avaliando quatro épocas de aplicação de N: 20 dias antes da semeadura, todo o $\mathrm{N}$ na semeadura, 15 dias após a emergência (DAE) e aos 35 DAE; duas formas de aplicação do N: superficial a lanço em área total e incorporado na entrelinha da cultura, observaram que a altura de planta em todos os tratamentos se correlacionou positiva e significativamente com a produtividade de grãos de milho, com valor de $\mathrm{r}$ de $0,87^{* *}$. Uma planta bem nutrida em $\mathrm{N}$ apresenta maior crescimento da área foliar e do sistema radicular, pois este nutriente influencia a divisão, a expansão celular e a fotossíntese, o que leva ao aumento da altura de plantas (Büll, 1993; Varvel et al., 1997).

Normalmente, o diâmetro do colmo apresenta correlação com a produtividade por se tratar de um órgão de reserva da planta. De acordo com Fancelli \& Dourado-Neto (2000), o colmo atua como estrutura de armazenamento de sólidos solúveis que serão utilizados posteriormente, na formação dos grãos. Na cultivar AG-9010, esta correlação não foi observada. As razões desses resultados não foram identificadas; trata-se, possivelmente, de um componente com importante controle genético intrínseco da cultivar; sabe-se, porém, que o mesmo apresenta baixa plasticidade de tamanho de espigas. É possível que o diâmetro de colmo também tenha o mesmo comportamento.

Os componentes da produção das cultivares estudadas se encontram na Tabela 4; a análise de variância mostrou não haver efeito significativo para a interação entre o efeito de parcelas e subparcelas mas, sim, variação significativa na população final de plantas com relação às cultivares utilizadas. As cultivares AL-34 e TRACTOR apresentaram uma população final abaixo da média recomendada, que é em torno de 50.000 plantas ha ${ }^{-1}$; contudo, este fato esteve relacionado com à baixa germinação das citadas cultivares. A semente do AL-34 não recebeu tratamento químico para controle de pragas e doenças, o que pode ter sido a causa do menor índice de germinação deste material; no caso do TRACTOR, as causas são desconhecidas, mas um possível armazenamento inadequado das sementes deste híbrido pode ter reduzido seu poder de germinação. O número de espigas apresentou o mesmo comportamento da população de plantas já que o índice de espigas mostrou comportamento semelhante, variando de 0,82 e 0,89 para todas as cultivares.

Tabela 4. Componentes da produção do milho em SPD nos Tabuleiros Costeiros do Estado de Alagoas

\begin{tabular}{lccccc}
\hline Cultivar & $\begin{array}{c}\text { População } \\
\text { de plantas } \\
\text { plantas ha-1 }\end{array}$ & $\begin{array}{c}\text { Número de } \\
\text { espigigas } \\
\text { espa-1 }\end{array}$ & $\begin{array}{c}\text { Fileiras } \\
\text { de grãos } \\
\text { Fileiras } \\
\text { espiga }\end{array}$ & $\begin{array}{c}\text { Comp. } \\
\text { de espiga } \\
\text { cm }\end{array}$ & $\begin{array}{c}\text { Massa de } \\
\text { 100 grãos }\end{array}$ \\
AL-34 & $37.813 \mathrm{~B}$ & $31.953 \mathrm{~B}$ & $13,43 \mathrm{~B}$ & $14,83 \mathrm{~A}$ & $24,90 \mathrm{~A}$ \\
DKB-395 & $51.993 \mathrm{~A}$ & $45.507 \mathrm{~A}$ & $13,98 \mathrm{~A}$ & $13,38 \mathrm{CD}$ & $25,54 \mathrm{~A}$ \\
DOW-8550 & $52.109 \mathrm{~A}$ & $42.539 \mathrm{~A}$ & $12,78 \mathrm{C}$ & $14,69 \mathrm{AB}$ & $24,53 \mathrm{~A}$ \\
TRACTOR & $41.250 \mathrm{~B}$ & $34.726 \mathrm{~B}$ & $13,49 \mathrm{~B}$ & $12,84 \mathrm{D}$ & $24,70 \mathrm{~A}$ \\
AG-9010 & $49.414 \mathrm{~A}$ & $44.257 \mathrm{~A}$ & $13,34 \mathrm{~B}$ & $13,97 \mathrm{BC}$ & $25,14 \mathrm{~A}$ \\
DMS & 6550 & 6.343 & 0,36 & 0,86 & 1,79 \\
CV\% & 12,49 & 14,13 & 2,4 & 5,47 & 6,36 \\
\hline
\end{tabular}

Médias seguidas de letras diferentes na coluna diferem estatisticamente pelo Teste de Tukey a $5 \%$ de probabilidade

Os valores médios do número de fileiras de grãos por espiga mostraram efeitos significativos entre as diferentes cultivares. A cultivar DKB-395 foi superior às demais. O híbrido DOW-8550 deteve a menor média, e as demais, intermediárias e não apresentando diferenças estatísticas entre si, cujo componente é determinado no estádio fenológico 1. De acordo com Fancelli \& Dourado-Neto (1997), este evento coincide com a segunda semana após a emergência, fase em que se inicia a formação dos primórdios da espiga. A falta de água e nutrientes nesta fase pode afetar esses componentes porém, como as condições experimentais eram as mesmas para todas as cultivares as diferenças obtidas provieram da influência genética de cada cultivar. 
Tomazela (2005) não encontrou diferença para o número de fileiras de grãos por espiga entre as cultivares e as doses de $\mathrm{N}$ utilizadas.

Os valores médios da massa de 100 grãos não indicaram variações significativas entre as cultivares. Segundo Ohland et al. (2005), o peso da massa de grãos é uma característica influenciada pelo genótipo, pela disponibilidade de nutrientes e pelas condições climáticas durante os estádios de enchimento dos grãos. De acordo com Ulger et al. (1995), este componente tem alta dependência da absorção de $\mathrm{N}$ pelo milho, a qual alcança um pico durante o período compreendido entre o início do florescimento e o início da formação de grãos (Arnon, 1975). A deficiência de $\mathrm{N}$, neste período, pode concorrer para a formação de grãos com menor massa específica, devido à não translocação em quantidades adequadas para os mesmos; entretanto, Silva et al. (2003), estudando doses de N (0; 40; 80 e $120 \mathrm{~kg} \mathrm{~N} \mathrm{ha}^{-1}$ ) na cultura do milho, não observaram efeito significativo no peso de 100 grãos.

As produtividades dos materiais utilizados no experimento variaram de $1.900 \mathrm{~kg} \mathrm{ha}^{-1}$ na testemunha a $5.662 \mathrm{~kg} \mathrm{ha}^{-1}$ para as maiores doses (Figura 2A; Figura 2B; Figura 2C; Figura 2D e Figura 2E). Se considerando que a produtividade média de grãos do Estado de Alagoas está em torno de $344 \mathrm{~kg} \mathrm{ha}^{-1}$, as produtividades alcançadas neste trabalho são reconhecidamente altas. O comportamento da cultivar AL-34 apresentou efeito quadrático, enquanto nas demais este efeito foi linear. Por se tratar de uma variedade, a AL-34 não possui o alto potencial produtivo encontrado nos híbridos que, por sua vez, são produzidos com características genéticas extremamente voltadas à alta produtividade. A dose de máximo rendimento agronômico calculado para a AL-34 foi de 116,5 $\mathrm{kg} \mathrm{ha}^{-1}$ de $\mathrm{N}$, dose em que a produtividade foi de $3,86 \mathrm{t} \mathrm{ha}^{-1}$. Salienta-se que a população de plantas desta cultivar esteve abaixo da recomendada. É provável que, se for considerada uma população recomendada de 50.000 plantas ha $^{-1}$, a produtividade poderá aumentar consideravelmente; nas demais cultivares, a dose de 120 kg ha-1 não alcançou a máxima produtividade agronômica, significando que os materiais poderiam apresentar maiores rendimentos com doses mais elevadas de $\mathrm{N}$ (Figura 2A; Figura 2B; Figura 2C; Figura 2D e Figura 2E).

Duarte (2003) também verificou, em seu trabalho, diferenças entre as cultivares em relação à resposta à aplicação de $\mathrm{N}$ em cobertura, assim como variação no padrão de exigência de $\mathrm{N}$ nos estádios iniciais de crescimento, bem como a ausência de resposta à aplicação de N (plantio e cobertura) para dose superior a $120 \mathrm{~kg} \mathrm{ha}^{-1}$.

Aumento na produção de grãos $\left(7575 \mathrm{~kg} \mathrm{ha}^{-1}\right.$ e 8686 $\left.\mathrm{kg} \mathrm{ha}^{-1}\right)$ em relação a doses crescentes de N (100 kg ha-1 de $\mathrm{N}$ e $200 \mathrm{~kg} \mathrm{ha}^{-1}$ de $\mathrm{N}$ respectivamente) foi relatado por Tomazela (2005) em trabalho desenvolvido no município de Piracicaba, SP, cujos resultados corroboram com as afirmações de Cantarella \& van Raij (1986) apud Ohland et al. (2005), os quais relatam que, em geral, 70 a 90\% dos experimentos com milho executados em campo no Brasil responderam à aplicação de nitrogênio. Silva et al. (2003) estudando os efeitos da aplicação de doses de nitrogênio (0, 40, 80 e

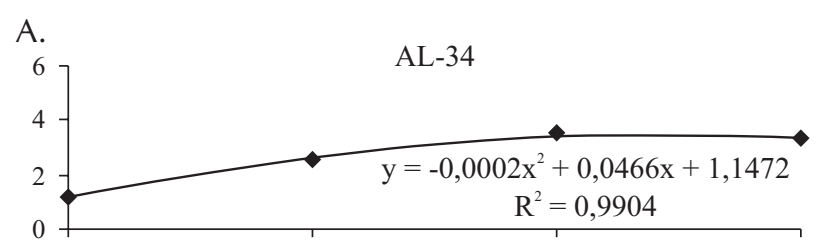

B.
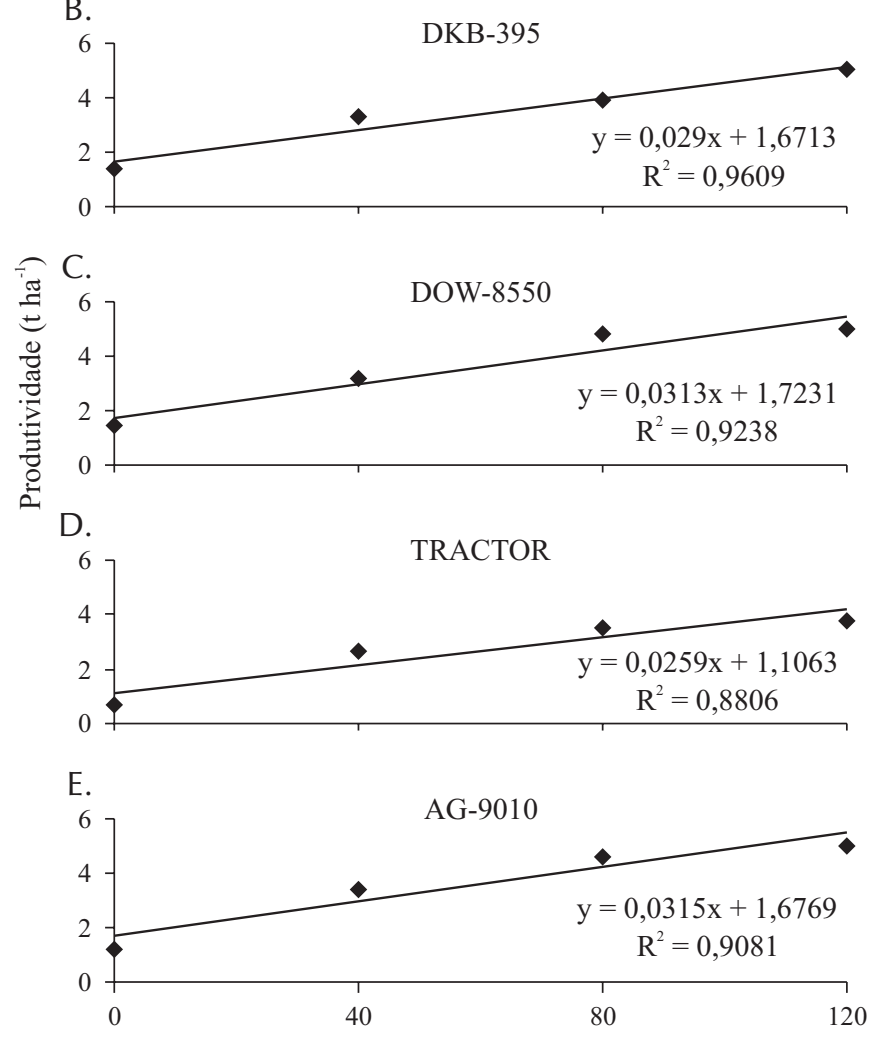

Figura 2. Produtividade de grãos de milho em função de doses de $\mathrm{N}$, em sistema plantio direto, AL-34 (A); DKB-395 (B); DOW-8550 (C); TRACTOR (D) e AG-9010 (E)

120 kg N ha-1) na cultura do milho, observaram que o nitrogênio aumentou o rendimento de grãos, linearmente; esses dados corroboram com os obtidos por Ferreira (1997) e Cazetta et al. (2005) que observaram aumento significativo na produção de milho cultivado em Sistema Plantio Direto em razão de incrementos nas doses de N. Yamada (1997) relatou rendimentos da ordem de $9500 \mathrm{~kg} \mathrm{ha}^{-1}$ a partir do fornecimento de $40 \mathrm{~kg} \mathrm{ha}^{-1}$ de $\mathrm{N}$ na semeadura, completados com adição de 80 a $90 \mathrm{~kg} \mathrm{ha}^{-1}$ em cobertura no estádio V4.

Todos os materiais utilizados neste trabalho apresentaram alta eficiência na utilização do N aplicado, haja vista o rendimento de grãos produzido por quilograma de N (Tabela 5); resultados inferiores foram encontrados por Ceretta (1998), utilizando 30, 60 e $90 \mathrm{~kg} \mathrm{ha}^{-1}$ de N em pré-semeadura, proporcionando um aumento de 10, 13 e 18 kg de grãos $\mathrm{kg}^{-1}$ de N aplicado e Oliveira \& Caires (2003), os quais obtiveram aumento médio na produção de 15,59 kg de grãos para cada $\mathrm{kg}$ de $\mathrm{N}$ aplicado em cobertura, com doses de 30, 60, 90 e $120 \mathrm{~kg} \mathrm{ha}^{-1}$ de $\mathrm{N}$ em sistema plantio direto.

O cálculo da responsividade, por sua vez, permitiu a formação de dois grupos de resposta, o primeiro formado pelas cultivares AL-34 e TRACTOR e o segundo pelas demais 
Tabela 5. Análise econômica da produção de grãos de milho em função das cultivares

\begin{tabular}{|c|c|c|c|c|c|c|}
\hline Cultivar & $\begin{array}{l}\text { Máxima dose } \\
\text { agronômica }\end{array}$ & $\begin{array}{l}\text { Produtividade na máxima } \\
\text { dose agronômica }\end{array}$ & $\begin{array}{l}\text { Rendimento de grãos } \\
\text { por kg de N aplicado }\end{array}$ & Gasto de $N$ ha $^{-1 *}$ & Receita ha-1** & $\begin{array}{l}\text { Receita kg-1 } \\
\text { de N aplicado }\end{array}$ \\
\hline & $\mathrm{kg} \mathrm{ha}^{-1}$ de $\mathrm{N}$ & t ha-1 de grãos & kg & & $\mathbf{R} \$$ & \\
\hline AL-34 & 116 & 3,9 & 33,6 & 12,76 & $1.430,00$ & 112,00 \\
\hline DKB-395 & 120 & 5,1 & 42,5 & 13,20 & $1.870,00$ & 141,66 \\
\hline DoW-8550 & 120 & 5,5 & 45,8 & 13,20 & $2.016,00$ & 152,00 \\
\hline TRACTOR & 120 & 4,2 & 35,0 & 13,20 & $1.540,00$ & 116,66 \\
\hline AG-9010 & 120 & 5,5 & 45,8 & 13,20 & $2.016,00$ & 152,00 \\
\hline
\end{tabular}

* Gasto de $\mathrm{N}$ para atingir a máxima dose agronômica. ${ }^{* *}$ Receita obtida na máxima dose agronômica. Preço do $\mathrm{N}=\mathrm{R} \$ 0,11 \mathrm{~kg}^{-1}$. Preço do milho $=\mathrm{R} \$ 0,36 \mathrm{~kg}^{-1}$

cultivares. Para cada quilograma de $\mathrm{N}$ aplicado foram produzidos 33,6 e 35,0 kg de grãos, para as cultivares AL-34 e TRACTOR, respectivamente, enquanto a menor responsividade foi afetada principalmente pela menor população final de plantas.

O segundo grupo, formado por (DKB-395, DOW-8550 e AG-9010), produziu em média 44,7 kg de grãos para cada quilograma de $\mathrm{N}$ aplicado, fazendo valer o maior potencial produtivo dessas cultivares em relação às do primeiro grupo.

As diferenças de potencial produtivo entre as cultivares estão de acordo com os dados obtidos por Ulloa et al. (1982), Purcino et al. (1994), Osaki (1995) e Casagrande \& Fornasieri Filho (2002), que mostram diferentes respostas ao uso de recursos em cada germoplasma testado.

A análise econômica permitiu inferir que o rendimento de grãos por quilograma de $\mathrm{N}$ aplicado foi satisfatório e, ao agricultor, um bom retorno sobre o capital empregado, na forma de adubação nitrogenada.

\section{CONCLUSÕES}

1. Em condições climáticas normais e solo com fertilidade satisfatória, a utilização de $120 \mathrm{~kg} \mathrm{ha}^{-1}$ de $\mathrm{N}$ permite ao agricultor retorno econômico da adubação nitrogenada.

2. Os materiais genéticos utilizados mostraram alta eficiência na utilização do $\mathrm{N}$ aplicado, sendo as cultivares DKB-395, DOW-8550, e AG-9010 mais responsivas que as cultivares AL-34 e TRACTOR.

\section{LITERATURA CITADA}

Agrianual. Anuário Agrícola Brasileiro. São Paulo: Argos Comunicação, 520p. 2005.

Amado, T. J. C.; Mielniczuk, J.; Aita, C. Recomendação de adubação nitrogenada para o milho no RS e SC adaptada ao uso de culturas de cobertura do solo, sob plantio direto. Revista Brasileira de Ciência do Solo, Viçosa, v.26, n.1, p.241248, 2002.

Arnon, I. Mineral nutrition of maize. Bern: International Potash Institute, 1975. 452p.

Bayer, M. M.; Todd, C. D.; Hoyle, J. E.; Wilson, J. F. B. Waverelated abrasion induces formation of extended spines in a marine bryozoan. Proceedings of the Royal Society of London, Series B, n.264, p.1605-1611, 1997.
Bernardi, A. C. C.; Machado, P. L. O. A.; Freitas, P. L.; Coelho, M. R.; Leandro, W. M.; Oliveira Júnior, J. P.; Oliveira, R. P.; Santos, H. G.; Madari, B. E.; Carvalho, M. C. S. Correção do solo e adubação no sistema de plantio direto nos cerrados. Rio de Janeiro: Embrapa Solos, 2003. 22 p. Documentos, 46.

Büll, L. T. Nutrição mineral do milho. In: Büll, L. T.; Cantarella, H., (ed.). Cultura do milho: Fatores que afetam a produtividade. Piracicaba: POTAFOS, 1993. p.63-146.

Casagrande, J. R. R.; Fornasieri Filho, D. Adubação nitrogenada na cultura do milho safrinha. Pesquisa Agropecuária Brasileira, Brasília, v.37, n.1, p.33-40, 2002.

Cazetta, D. A.; Fornasieri Filho, D.; Girotto, F. Efeitos da cobertura vegetal e da adubação nitrogenada sobre os componentes de produção do milho em sistema de semeadura direta. Acta Scientiarum Agronomy, Maringá, v.27, n.4, p.567-573, 2005.

Ceretta, C. A. Adubação nitrogenada no sistema plantio direto: sucessão aveia/milho. In: Conferência Anual de Plantio Direto, 2, 1998, Ijuí. Anais... Passo Fundo; Aldeia Norte, 1998, p.49-62.

Coelho, A. M.; França, G. E.; Bahia Filho, A. F. C.; Guedes, G. A. A. Doses e métodos de aplicação de fertilizantes nitrogenados na cultura do milho sob irrigação. Revista Brasileira de Ciência do Solo, Campinas, v.16, n.1, p.61-67, 1992.

Duarte, A. P. Resposta de cultivares de milho ao nitrogênio no sistema plantio direto e sua influência na qualidade de grãos. Piracicaba: ESALQ/USP 2003. 174p. Tese Doutorado

EMBRAPA - Empresa Brasileira de Pesquisa Agropecuária. Centro Nacional de Pesquisa de Solos. Manual de métodos de análise de solo. 2.ed. Rio de Janeiro: EMBRAPA, 1997. 212p.

EMBRAPA - Empresa Brasileira de Pesquisa Agropecuária. Centro Nacional de Pesquisa de Solos. Sistema brasileiro de classificação de solos. Rio de Janeiro: EMBRAPA, 1999. 412p.

Fancelli, A. L. Cultura do milho: A importância da tecnologia. Informações Agronômicas, Piracicaba, v.1, n.78. p.4-6. 1997.

Fancelli, A. L.; Dourado-Neto, D. Milho: Ecofisiologia e rendimento. In: Fancelli, A.L.; Dourado-Neto, D., (coords.). Tecnologia da produção de milho. Piracicaba: ESALQ/USP, 1997. p.157-170.

Fancelli, A. L.; Dourado-Neto, D. Produção de milho. Guaíba: Agropecuária, 2000. 360p.

Fernandes, A. L.; Furtini Neto, A. E.; Vasconcelos, C. A.; Guedes, G. A. A. Preparo do solo e adubação nitrogenada na produtividade do milho em latossolo sob vegetação de cerrado. Revista Brasileira de Ciência do Solo, Campinas, v.22, n.2, p.247-254, 1998.

Ferreira, A. C. B. Efeitos da adubação de N, Mo e Zn sobre a produção, qualidade de grãos e concentração de nutrientes no milho. Viçosa: UFV, 1997. 74p. Dissertação Mestrado 
Gonçalves, C. N.; Cereta, C. A.; Basso, C. J. Sucessões de culturas com plantas de cobertura e milho em plantio direto e sua influência sobre o nitrogênio do solo. Revista Brasileira de Ciência do Solo, Viçosa, v.24, n.1, p.153-159, 2000.

Karlen, D. L; Flanery, R. L.; Sadler, E. J. Aerial accumulation and partitioning of nutrients by corn. Agronomy Journal, Madison, v.80, n.2, p.232-42, 1988.

Lara Cabezas, W. A. R.; Trivelin, P. C. O.; Kornodôrf, G. H.; Pereira, S. Balanço da adubação nitrogenada sólida e fluida de cobertura na cultura do milho em sistema plantio direto no Triângulo Mineiro. Revista Brasileira de Ciência do Solo, Viçosa, v.14, n.2, p.363-376, 2000.

Müller Mai. M. E.; Ceretta, C. A.; Basso, C. J.; Silveira, M. J. da, Pavinato, A.; Pavinato, P. F. Manejo da adubação nitrogenada na sucessão aveia-preta/milho no sistema plantio direto. Pesquisa Agropecuária Brasileira, Brasília, v.38, n.1, p.125-131, 2003.

Ohland, R. A. A.; Souza, L. C. F.; Machetti, M. E.; Gonçalves, M. C. Culturas de cobertura do solo e adubação nitrogenada no milho em plantio direto. Ciência e Agrotecnologia, Lavras, v.29, n.3, p.538-544, 2005.

Oliveira, J. M. S. de; Caíres, E. F. Adubação nitrogenada em cobertura para o milho cultivado após aveia preta no sistema plantio direto. Acta Scientiarum Agronomy, Maringá, v.25, n.2, p.351-357, 2003.

Osaki, M. Comparison of productivity between tropical and temperate maize. Soil Science and Plant Nutrition, Tokyo, v.41, n.3, p.439-450, 1995.

Purcino, A. A. C.; Magnavaca, R.; Machado, A. T.; Marriel, E. E. Atividade da redutase do nitrato em genótipos antigos e modernos de milho, cultivados sob dois níveis de nitrogênio. Revista Brasileira de Fisiologia Vegetal, Londrina, v.6, n.1, p.41-46, 1994.
Sá, J. C. M. Sistema de produção de milho visando alta produtividade na região dos campos gerais no centro-sul do Paraná. In: Büll, L. T.; Cantarela, H. Cultura do milho: Fatores que afetam a produtividade. Piracicaba: POTAFOS, 1993, 301p.

Silva, E. C. da; Ferreira, S. M.; Silva, G. P.; Assis, R. L. de; Guimarães, G. L. Épocas e formas de aplicação de nitrogênio no milho sob plantio direto em solo de cerrado. Revista Brasileira de Ciência do Solo, Viçosa, v.29, n.5, p.725733, 2005.

Silva, P. S. L.; Oliveira, F. H. T. de; Silva, P. I. B. Efeitos da aplicação de doses de nitrogênio e densidades de plantio sobre os rendimentos de espigas verdes e de grãos de milho. Horticultura Brasileira, Brasília, v.21 n.3, p.454-457, 2003.

Tomazela, A. L. Adubação nitrogenada e de micronutrientes na produtividade e incidência de doenças foliares em milho. Piracicaba: ESALQ/USP 2005. 58p. Dissertação Mestrado

Ulger, A. C.; Becker, A. C.; Khant, G. Response of maize inbred lines and hybrids to increasing rates of nitrogen fertilizer. Journal of Agronomy and Crop Science, Berlin, v.159, n.1, p.157163, 1995.

Ulloa, A. M. C.; Libardi, P. L.; Reichardt, K. Utilização do nitrogênio fertilizante por dois híbridos de milho. Campinas: Fundação Cargill, 1982. 66p.

Varvel, G. E.; Schpers, J. S.; Francis, D. D. Ability for in-season correction of nitrogen deficiency in corn using chlorophyll meters. Soil Science Society of America Journal, Madison, v.61, n.4, p.1233-1239, 1997.

Yamada, T. Nitrogênio e potássio na adubação da cultura do milho. Informações Agronômicas. POTAFOS, Piracicaba, v.1, n.78, p.1-4, 1997. 